\title{
Traduire
}

Une autre perspective sur r tr traduction

Revue française de la traduction

$223 \mid 2010$

Tribunal et théâtre, faites entrer le traducteur

\section{Brice Matthieussent, Vengeance du traducteur}

\section{Freddie Plassard}

\section{OpenEdition}

\section{Journals}

Édition électronique

URL : http://journals.openedition.org/traduire/328

DOI : 10.4000/traduire.328

ISSN : 2272-9992

\section{Éditeur}

Société française des traducteurs

\section{Édition imprimée}

Date de publication : 15 décembre 2010

Pagination : 141-142

ISSN : 0395-773X

\section{Référence électronique}

Freddie Plassard, «Brice Matthieussent, Vengeance du traducteur », Traduire [En ligne], 223 | 2010, mis en ligne le 21 mai 2014, consulté le 22 septembre 2020. URL : http://journals.openedition.org/traduire/ 328 ; DOI : https://doi.org/10.4000/traduire.328 


\section{Compte rendu d'ouvrage Brice Matthieussent, Vengeance du traducteur, Roman, Paris, P.O.L., 2009}

\section{Freddie Plassard}

Brice Matthieussent livre, avec Vengeance du traducteur, le fruit ludique de réflexions inspirées par une pratique qui lui vaut aujourd'hui une renommée internationale et un palmarès de non moins de deux cent traductions d'auteurs contemporains principalement américains. Le roman aborde la question de la traduction sous l'angle de l'espace réservé au traducteur, tant sur la page que dans la littérature ou l'écriture en général. L'idée lui en serait venue de sa tendance, en début de carrière, à abuser des notes de bas de page, très souvent supprimées par l'éditeur.

Construit selon le principe de la mise en abyme et des emboîtements narratifs, le roman met en scène la prise de pouvoir progressive de David Grey, traducteur, sur Abel Prote, auteur du roman Translator's Revenge, dans une lutte sans merci au dénouement néanmoins attendu, la mise à mort de l'auteur. Brice Mathieussent donne la parole au traducteur - ou la prend en son nom - sous la forme d'une note de bas de page qui ne cesse, tout au long du roman, de gagner du terrain sur une page initialement plutôt blanche, tandis que le texte principal dont elle est une forme de commentaire reste paradoxalement invisible. C'est donc la parole réputée seconde du traducteur qui occupe ici le devant de la scène, lui qui, d'ordinaire, est a prioriprivé d'énonciation en son nom propre.

Riche en rebondissements, anecdotes savoureuses et pages mémorables, le roman se prête de fait à une multiplicité de lectures dont celle, progressivement délinéarisée, truffée de chasséscroisés et d'épisodes insolites, de la "fabula ", centrée sur le thème de la vengeance, et celle, plus réflexive, qui confère à la trame romanesque une portée traductologique, parfois induite par les allusions et reprises intertextuelles, ne serait-ce que celle du nom du père de l'auteur, Maurice-Edgar Prote. Loin d'aborder métaphores, topoï et problématiques associés à la traduction de manière frontale et théorique, Brice Matthieussent leur donne vie, les met en scène : ne voit-on pas David Grey évoluer dans un monde double à plusieurs égards, géographique, historique et textuel, brouillant à loisir les repères du réel et de la fiction à l'intérieur même de la fiction, pour en conclure que "c'est la vie qui imite l'art, jamais l'inverse " (p. 257). 
La diversité des métaphores de l'activité de traduction et de la figure du traducteur supplante ici la réflexion théorique.

S'affranchissant de la double autorité de l'auteur et du texte de départ, le traducteur-narrateur affirme ses propres valeurs esthétiques : prédilection pour le fragment, le décentrement et l'hermétisme et rejet de la " pose insipide ", de la " prose faisandée ", de "l'ostentation vaniteuse " ou du " méprisable désir de statue " qui anime l'auteur. C'est ici la partie qui se voit privilégiée au détriment du tout, synecdoque aidant, tandis que la geste du traducteur se voit assimilée à un recyclage, un réemploi des déchets, restes, bribes et résidus langagiers et textuels.

Si le texte vit sa vie, une fois affranchi de la tutelle de l'auteur et du traducteur, les plaisirs de l'écriture, part essentielle de l'activité du traducteur, sont vantés sur le mode du plaisir érotique et d'une liberté que plus rien ne vient entraver. Les limites assignées au traducteur n'en sont pas moins clairement posées : " pourvu qu'il demeure humble, enthousiaste et zélé, modeste et rigoureux. (...). Pourvu, surtout, qu'il ne se prenne pas pour un écrivain. „ (p. 309) !

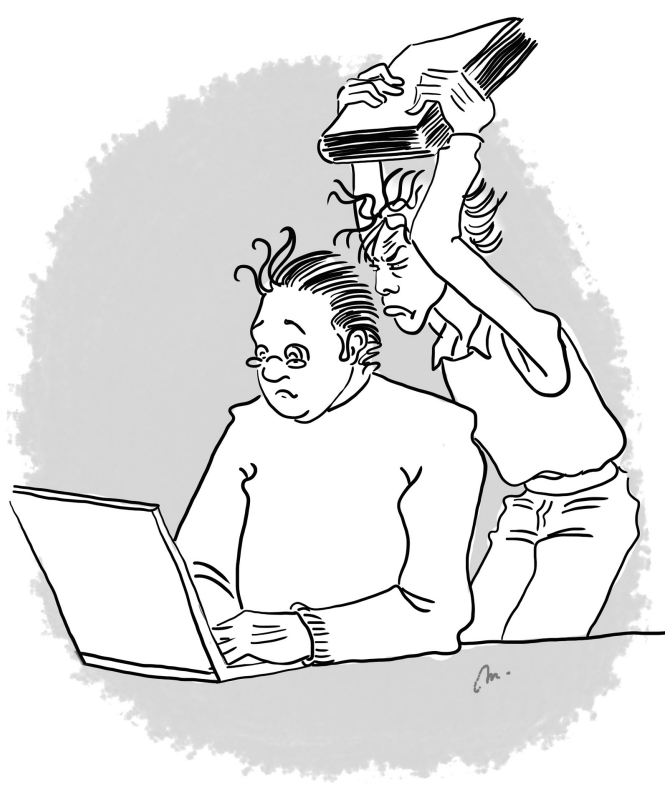

Illustration : Marlène Junius, http://alotoftralala.over-blog.com 